\title{
Proteinúria: como valorizar o seu significado
}

\author{
FRANCISCO FERRER,* NUNO OLIVEIRA,* KARINA LOPES,* ANA FIGUEIREDO,** \\ PEDRO MAIA, ${ }^{* * *}$ ARMANDO CARREIRA****
}

\begin{abstract}
RESUMO
Introdução: A proteinúria é um achado laboratorial comum em adultos assintomáticos, que em circunstância alguma deve ser menosprezado. A utilização de tiras teste é o método mais utilizado na detecção da proteinúria, mas, como apresenta uma elevada taxa de falsos positivos, impõe-se a utilização de outros métodos na sua confirmação/monitorização.

Objectivos: Efectuar uma revisão dos principais mecanismos fisiopatológicos de proteinúria e dos métodos actualmente utilizados na sua detecção e quantificação. Discutir a sua importância clínica e apresentar um possível protocolo de abordagem diagnóstica. Rever as terapêuticas específicas disponíveis, principalmente no contexto da Doença Renal Crónica (DRC).

Metodologia: Foi realizada uma pesquisa na Pubmed de artigos originais, de artigos de revisão e de meta-análises até Abril de 2007 e foram consultadas fontes documentais de referência, nas áreas da Nefrologia e da Medicina Interna. Foram ao todo incluídos 63 artigos.

Conclusões: A utilização de um algoritmo diagnóstico ajuda na distinção entre as causas benignas (doença febril, exercício físico, desidratação...) de outras causas menos frequentes, mas mais graves (glomerulopatias, gamapatias monoclonais...). A presença de proteinúria deve ser confirmada obrigando a estudo complementar, nomeadamente com análises quantitativas (proteinúria das 24 horas ou razão proteína/creatinina em amostra aleatória de urina). Os doentes com proteinúria persistente e cuja causa para a mesma não se identifica após investigação clínica, devem referenciados à consulta de Nefrologia. Nos doentes renais crónicos, a detecção e o tratamento precoces da proteinúria melhoram o prognóstico a curto e a longo prazo. Considerando o aumento da prevalência da DRC na população geral, o Médico de Família tem um papel preponderante na identificação dos individuos em risco de doença renal e na vigilância dos factores de risco a ela associados, designadamente da proteinúria.
\end{abstract}

Palavras Chave: Proteinúria; Microalbuminúria; Doença Renal Crónica.

*Interno Complementar de Nefrologia Serviço de Nefrologia do Centro Hospitalar de Coimbra **Director de Serviço Serviço de Medicina Interna do Centro Hospitalar de Coimbra ***Assistente Graduado de Nefrologia Serviço de Nefrologia do Centro Hospitalar de Coimbra ****Director de Servico Serviço de Nefrologia do Centro Hospitalar de Coimbra

\section{INTRODUCÃO}

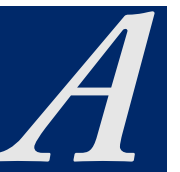

proteinúria é muitas vezes um achado detectado num exame de rotina à urina. Na maioria dos casos transitória e benigna, a sua persistência pode traduzir nefropatia primária ou secundária a doença sistémica. Pode representar os estádios iniciais de doença renal crónica (DRC), ser um marcador ou mesmo factor de risco para a doença cardiovascular (DCV). Os indivíduos com proteinúria têm um aumento do risco de morte; ${ }^{1}$ por isso mesmo, hipertensos e diabéticos são uma população alvo, em que se deve monitorizar regularmente a pro- teinúria (ou a microalbuminúria, nas fases precoces), já que está bem documentado que a sua presença condiciona um pior prognóstico. É discutivel a extensão deste rastreio à população geral assintomática e sem doenças relevantes subjacentes. ${ }^{2,3}$

\section{OBJECTIVO}

Efectuar uma revisão dos principais mecanismos fisiopatológicos de proteinúria e dos métodos actualmente utilizados na sua detecção e quantificação. Discutir a sua importância clínica e apresentar um possivel protocolo de abordagem diagnóstica. Rever as terapêuticas específicas 
disponiveis, principalmente no contexto da DRC.

\section{METODOLOGIA}

Foi realizada uma pesquisa na Pubmed de artigos originais, de artigos de revisão e de meta-análises até Abril de 2007, incidindo particularmente nos últimos cinco anos.

Foram utilizadas as seguintes palavras-chave: proteinúria, microalbuminúria, fisiopatologia de proteinúria, diagnóstico de proteinúria, proteinúria na doença renal crónica e tratamento da proteinúria (proteinuria, microalbuminuria, physiopathology of proteinuria, diagnostic of proteinuria, proteinuria in chronic kidney disease, treatment of proteinuria).

Optou-se pela selecção de todos os artigos cujo título e resumo fossem considerados de interesse para a revisão em causa. Posteriormente, obtiveram-se os artigos em texto integral.

Procedeu-se ainda a uma pesquisa documental em obras de referência nas especialidades de Medicina Interna $^{11}$ e de Nefrologia ${ }^{6,7,15,17,18,21}$ e no

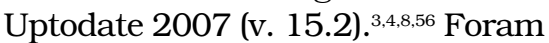
ao todo incluídos 63 artigos.

\section{DEFINICÃO}

Há 24 séculos Hipócrates estabeleceu a associação entre turvação da urina e doença renal. Hoje, proteinúria é definida como a excreção urinária de proteínas superior a 150 mg por dia, embora fases precoces de certas doenças renais possam cursar com menores graus de proteinúria (Quadro I). ${ }^{4}$ Convém no entanto salientar que na gravidez a excreção urinária de proteínas aumenta, sendo considerados como pato-

\begin{tabular}{|c|c|}
\hline \multicolumn{2}{|c|}{ QUADRO I } \\
\hline \multicolumn{2}{|c|}{$\begin{array}{c}\text { CLASSIFICAC̣ÃO DA EXCREC̣̃O DIÁRIA } \\
\text { DE PROTEÍNAS (MG/24 H) }\end{array}$} \\
\hline \multicolumn{2}{|l|}{ Proteínas totais } \\
\hline Normal (adultos) & $<150$ \\
\hline Proteinúria & $>150$ \\
\hline Nefrótica & $>3500$ \\
\hline \multicolumn{2}{|l|}{ Albumina } \\
\hline Normal & $2-30$ \\
\hline Microalbuminúria & $30-300$ \\
\hline Macroalbuminúria & $>300$ \\
\hline
\end{tabular}

lógicos níveis de proteinúria superiores a $300 \mathrm{mg} /$ dia.

Microalbuminúria define-se como a excreção urinária de albumina entre 30 e 300 mg/dia ou 20-200 ug/ /minuto, em duas determinações separadas por um intervalo superior a 3 meses. ${ }^{5}$ Utiliza-se sobretudo na identificação de doentes com diabetes em risco de nefropatia e na avaliação do risco cardiovascular, por exemplo, em doentes hipertensos.

Da totalidade de proteínas diariamente excretadas na urina, 20 a 30 mg correspondem a albumina, 10 a $20 \mathrm{mg}$ a proteínas plasmáticas de baixo peso molecular (como as cadeias leves de imunoglobulinas) e 40 a $60 \mathrm{mg}$ a proteínas secretadas pelo ramo ascendente da ansa de Henle e túbulo distal (destas, destacam-se a proteína de Tamm-Horsfall e a Imunoglobulina A). ${ }^{6}$

\section{Fisiopatologia da Proteinúria}

Do ponto de vista fisiopatológico, a proteinúria pode ser classificada como glomerular, tubular e de sobrecarga. $^{7}$

A proteinúria glomerular resulta do aumento da filtração de macromoléculas através da barreira de filtração glomerular (Figura 1), por

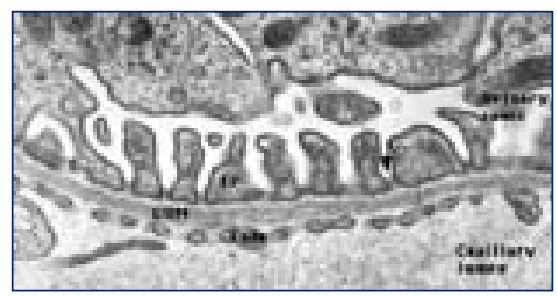

Figura 1. Barreira de filtração glomerular normal A imagem obtida por microscopia electrónica mostra as três camadas da barreira de filtração glomerular: 0 endotélio fenestrado (Endo), a membrana basal glomerular (GBM) e a célula epitelial com os podócitos (FP). Os podócitos estão separados entre si por fendas de filtração, que são fechados por uma membrana fina, o diafragma em fenda (seta).

Reproduced with permission from: Rose, BD. Evaluation of isolated proteinuria in adults. In: UpToDate, Rose, BD (Ed), UpToDate, Waltham, MA, 2007. Copyright 2007 UpToDate, Inc. For more information visit www.uptodate.com

dois mecanismos: perda de selectividade de carga e perda de selectividade de tamanho. ${ }^{8}$

As células endoteliais, a membrana basal glomerular (MBG) e as células epiteliais são revestidas por glicoproteínas polianiónicas, ${ }^{9}$ que criam uma barreira de carga à passagem de grandes moléculas que a $\mathrm{pH}$ fisiológico se comportam como aniões (como por exemplo a albumina).

Além da carga, também o tamanho das moléculas é factor de impedimento à filtração. As células endoteliais fenestradas apresentam poros de $100 \mathrm{~nm}$, que impedem a passagem de células e grandes partículas, mas não impedem a passagem de proteínas. A membrana basal glomerular não permite a passagem de proteínas com pesos moleculares superiores a $100 \mathrm{kDa}(\mathrm{a}$ albumina tem um peso molecular de $65 \mathrm{kDa}$ ); os diafragmas em fenda têm pequenos poros (40-45 Å) que ainda assim permitem a passagem de albumina (com um raio de $36 \AA$ ). ${ }^{10}$

A proteinúria na maioria das doenças glomerulares é devida a uma agressão estrutural (por exem- 
plo, por deposição de imunocomplexos), que resulta num aumento do número e do diâmetro dos poros perda da selectividade de tamanho. A perda parcial da selectividade de carga é um mecanismo menor na fisiopatologia deste tipo de proteínuria. Assim, há perdas urinárias de grandes quantidades de albumina e de outras proteínas plasmáticas proteinúria não selectiva. ${ }^{10,11}$ Pelo contrário, a proteinúria na doença de lesões mínimas da criança ocorre principalmente uma perda da selectividade de carga, provavelmente devido à redução na síntese de polianiões como o heparan-sulfato. Neste caso, a albumina é a principal proteína excretada - proteinúria selectiva; a filtração de macromoléculas neutras está apenas ligeiramente aumentada, o que sugere a manutenção da selectividade de tamanho. ${ }^{10,11}$

Os doentes com síndrome nefrótica apresentam uma permeabilidade inferior à normal para os pequenos solutos e para a água, devido a alterações como a esclerose glomerular, o espessamento da MBG ou a fusão dos podócitos. ${ }^{12,13}$ Isto resulta numa menor área de superficie para filtração e numa menor permeabilidade da barreira de filtração. No entanto, devido ao aumento do número de grandes poros, há um aumento da filtração de proteínas. ${ }^{14}$

A proteinúria tubular é constituída por proteínas de baixo peso molecular $(<25 \mathrm{kDa})$ como $\beta 2$-microglobulina, cadeias leves de imunoglobulina, proteína ligante de retinol e não ultrapassa em regra os $2 \mathrm{~g} /$ dia. $^{15}$ Estas proteínas são filtradas livremente através da barreira de filtração glomerular, sendo depois reabsorvidas quase por completo no túbulo proximal. A perturbação deste mecanismo ocorre em doenças tubulo-intersticiais ou mesmo com al- gumas glomerulopatias primárias, podendo neste caso coexistir proteinúrias glomerular e tubular. ${ }^{16}$

A proteinúria de sobrecarga é devida à presença de concentrações anormalmente elevadas de uma proteína plasmática, que é filtrada através da barreira de filtração glomerular mas que excede a capacidade de reabsorção tubular proximal. Está habitualmente associada à presença de cadeias leves de imunoglobulinas (ou seus fragmentos) - Proteinúria de Bence-Jones -, detectadas por electroforese ou imunoelectroforese das proteínas urinárias. Pode ser encontrada principalmente em doentes com mieloma múltiplo, e menos frequentemente na amiloidose e na doença de cadeias leves. ${ }^{15}$

Há ainda um outro tipo de proteinúria, a chamada proteinúria tecidular, que é constituída pelas proteínas produzidas pelas células do tracto urinário em situações de inflamação ou neoplasia das mesmas. Raramente ultrapassa os 500 mg/ /dia. ${ }^{17}$

\section{Métodos para Detecç̃o E Quantificaç̃o da Protennúria}

\section{Tiras Teste/Sumária de Urina}

É sem dúvida alguma o teste mais comummente utilizado para a detecção de proteinúria. Mede a concentração de proteínas através de uma reacção colorimétrica, entre as proteínas e o azul de tetrabromofenol, produzindo diferentes gradações de verde de acordo com a concentração de proteínas da amostra - método semi-quantitativo. Os resultados são apresentados numa escala de $0 \mathrm{a}+++$ ou ++++ , de acordo com o fabricante. ${ }^{18}$

Embora a utilização de tiras teste seja altamente específica na detecção da proteinúria, pode cursar com falsos positivos: urina alcalina $(\mathrm{pH}>$ 7.5); urina muito concentrada (densidade urinária $>1,026$ ); hematúria macroscópica (mas não microscópica); presença de penicilina, sulfamidas, clorohexidina ou tolbutamida; contaminação com secreções vaginais, sémen ou pús; utilização prévia de contrastes iodados. ${ }^{18,19}$

Por outro lado, é um método menos sensivel que os métodos quantitativos na avaliação da intensidade da proteinúria. Como detecta concentrações de proteínas e não valores absolutos, em presença de urina diluída (densidade $<1,006$ ) ou de baixas excreções diárias de proteínas pode fornecer resultados falsos negativos. As tiras teste só se tornam positivas com excreções diárias de proteínas superiores a 300$-500 \mathrm{mg} /$ dia; dados recentes sugerem que a análise combinada da densidade urinária e da proteinúria detectada por tira teste pode aumentar significativamente a capacidade de detecção de proteinúria..$^{18,20}$

As tiras teste são altamente específicas para a albumina, que é carregada negativamente; por isso podem fornecer falsos negativos em presença de proteínas catiónicas, como as cadeias leves de imunoglobulina ou a 32 -microglobulina - daí não ser um método adequado quando se suspeita de proteinúria de sobrecarga ou de proteinúria tubular. ${ }^{21}$

Para além da albumina, as tiras teste também são úteis na detecção da lisozima urinária, uma proteína que surge em concentrações urinárias aumentadas na leucemia mielo-monocítica aguda. ${ }^{4}$

\section{Tiras teste para a detecção de microalbuminúria}

Como as tiras teste só detectam excreções diárias de proteínas superiores a 300-500 mg/dia, não são adequados à detecção de microalbumi- 
núria. Para isso existem testes semi-quantitativos com tiras reagentes próprias (Clinitek Microalbumin $\AA$ e Micral Test II®); a sensibilidade e a especificidade destes variam entre os $80-97 \%$ e $33-80 \%$, respectivamente. ${ }^{22}$ Mesmo assim, e como os resultados destas tiras podem ser influenciados pelas variações nas concentrações da urina, estas devem apenas ser utilizadas quando não é possivel fazer uma avaliação quantitativa da microalbuminúria. ${ }^{23,24}$

\section{Testes de Turvação da urina}

São testes qualitativos, pouco utilizados actualmente, que se podem usar sempre que haja suspeita da presença de outra proteína na urina, que não a albumina (por exemplo em situações de insuficiência renal aguda inexplicada, com sedimento urinário benigno e sem proteínas urinárias detectáveis pelas tiras teste). Os dois mais utilizados são o Teste do Ácido Sulfossalicílico e o Teste de Precipitação pelo Calor.

O Teste do Ácido Sulfossalicílico detecta todo o tipo de proteínas urinárias (excepto a proteína de Tamm-Horsfall e a $\beta 1$-glicoproteína), ${ }^{21}$ através da mistura de uma amostra de $10 \mathrm{ml}$ de urina, com 8 gotas de solução de ácido sulfossalicílico a 20\%. A turvação resultante podem ser classificada entre 0 (sem turvação) e 4+ (floculação; > 500 mg de proteína/dl). Podem surgir falsos positivos em presença de urina muito concentrada, hematúria macroscópica, meios de contraste iodados, metabolitos das sulfamidas, miconazol, de derivados penicilinâmicos ou de cefalosporinas. A urina excessivamente alcalina ou diluída pode ser causa de falsos negativos. ${ }^{19}$

O Teste de Precipitação pelo Calor passa pela centrifugação de $5 \mathrm{ml}$ de urina, juntando-se depois $2 \mathrm{ml}$ de tampão acetato ao sobrenadante; a mistura é então aquecida a $56^{\circ} \mathrm{C}$. O aparecimento de precipitado é indicador da presença de proteínas de Bence-Jones. ${ }^{25}$

\section{Proteinúria das 24 horas}

Para se conhecer exactamente a quantidade de proteínas excretadas por dia, estas devem ser doseadas numa amostra de urina de 24 horas. Continua a ser o gold-standard na quantificação da proteinúria, já que a excreção de proteínas varia com ritmo circadiano. No entanto, os erros frequentes na colheita da amostra podem influenciar negativamente a sua interpretação. ${ }^{18}$

\section{Razão proteina/creatinina ou albumina/creatinina em amostra de urina aleatória}

Actualmente, começam-se a utilizar as razões albumina/creatinina ou proteína total/creatinina, numa amostra aleatória de urina (de preferência, na primeira da manhã), em alternativa à proteinúria de 24 horas. ${ }^{26,27}$ São exames mais simples de executar, com menores custos e maior comodidade para os doentes. Estes doseamentos correlacionam-se estreitamente com as excreções diárias de proteínas em g/1,73 m² de superfície corporal. ${ }^{28}$ A utilização destas razões baseia-se no facto da excreção diária de creatinina ser apenas ligeiramente superior a $1.000 \mathrm{mg} /$ dia por $1,73 \mathrm{~m}^{2}$ de superfície corporal. ${ }^{28}$

A quantificação da proteinúria deve ser realizada com a razão albumina/creatinina nas fases incipientes. Isto deve-se ao facto da microalbuminúria representar um nível de excreção de albumina acima do normal, mas abaixo do limiar de detecção dos testes utilizados no doseamento das proteínas totais. Assim, a utilização da razão proteína total/creatinina não detecta este ní- vel de proteinúria. Por outro lado, a determinação da excreção urinária de albumina é um marcador mais sensivel que a de proteína total na detecção de fases incipientes de doença renal devida a diabetes, a hipertensão ou a outras doenças glomerulares; nestas situações, a monitorização da evolução da doença deve ser feita com a razão albumina/creatinina.

O intervalo para definição de microalbuminúria utilizando a razão albumina/creatinina varia com o sexo, sendo de 20 a $200 \mathrm{mg} / \mathrm{g}$ para o sexo feminino e 30 a $300 \mathrm{mg} / \mathrm{g}$ para o sexo masculino. Estas diferenças traduzem a maior massa muscular dos indivíduos do sexo masculino. ${ }^{29}$

Se o doente tiver um resultado positivo para proteinúria em tira teste ou um nivel de proteinúria conhecido superior a $300-500 \mathrm{mg} /$ dia, a quantificação da proteinúria tanto pode ser feita com a razão albumina/creatinina, como com a razão proteina total/creatinina. Nesta situação, a proteinúria é constituída maioritariamente por albumina, daí ser semelhante a informação fornecida por ambas. Esta noção está de acordo com as recomendações para adultos das Kidney Diseases Outcomes Quality Initiative (K/DOQI). ${ }^{27}$

Ainda que, em ocasiões raras, estas razões podem fornecer falsos resultados, nomeadamente quando a excreção de creatinina é substancialmente diferente do valor esperado (massas musculares desenvolvidas ou atrofiadas; em negros ou mexicanos, duas raças em que a excreção de creatinina é superior). ${ }^{29}$ Uma outra limitação destas razões, quando aplicados numa amostra de urina ao acaso, prende-se com o facto de não poder ser utilizado no diagnóstico de situações em que a excreção de proteínas varia substancial- 
mente ao longo do dia, como acontece na proteinúria ortostática. ${ }^{26}$

\section{Electroforese das proteinas urinárias}

É um método para avaliação qualitativa da proteinúria, especialmente indicado na suspeita de proteinúria de sobrecarga. Identifica picos monoclonais na fracção gama, relacionados com a presença de cadeias leves de imunoglobulinas (proteínas de Bence-Jones) e característicos das discrasias plasmocitárias. A sua associação a imunofixação (imunoelectroforese) permite identificar o tipo de cadeia em causa $(\mathrm{k}$ ou $\lambda$ ), aumentando a sensibilidade para detecção da paraproteína. ${ }^{15,17}$

\section{Tipos de Proteinúria GLomerular}

Embora seja muito frequente a detecção de proteinúria num exame de rotina à urina, na maioria das vezes é transitória/funcional, de baixo grau ( $<1 \mathrm{~g} /$ dia), benigna e acabando por resolver em observações subsequentes. ${ }^{30}$ Está frequentemente associada a febre, exercício físico, desidratação ou exposição a temperaturas extremas. Neste tipo de proteinúria ocorre um aumento da excreção de albumina e de proteínas de baixo peso molecular, que pode ser explicado por um aumento da permeabilidade glomerular (mediado pela angiotensina II e pela noradrenalina) e por uma redução da reabsorção ao nível do túbulo proximal. ${ }^{3}$ Dentro deste tipo de proteinúria também é considerada a que surge associada a infecções urinárias sintomáticas, ${ }^{31,32}$ que por definição resolve com o seu tratamento.

A proteinúria ortostática ocorre principalmente em crianças e adolescentes (2-5\%), sendo caracterizada por aumento da excreção de pro-

\begin{tabular}{|l|}
\hline \multicolumn{1}{|c|}{ QUADRO II } \\
\hline CLASSIFICAÇ̃̃o ETIOLÓGICA DE PROTEINÚRIA ${ }^{16}$ \\
\hline Isolada \\
Transitória / Funcional \\
Ortostática \\
\hline Associada a doenças renais ou sistémicas \\
Não nefrótica (<3,5 g/dia) \\
Doença glomerular ligeira incluindo \\
Nefropatia de IgA) \\
Doença tubulo-intersticial \\
Necrose Tubular aguda \\
Hipertensão \\
Insuficiência cardiaca \\
Diabetes \\
Doenças do colagéneo \\
Mieloma múltiplo \\
Endocardite bacteriana \\
Infecção do Tracto Urinário \\
(incluindo tuberculose) \\
Nefrótica (> 3,5 g/dia) \\
Glomerulopatias primárias \\
Lesão mínima \\
Membranosa \\
Focal e segmentar \\
Nefropatia de IgA \\
Membranoproliferativa \\
Glomerulopatias secundárias \\
Diabetes \\
Pós-estreptocócica \\
Malignidade \\
Fármacos (ouro, AINEs*, heroína, \\
penicilamina) \\
Infecções (VIH, VHB e C) \\
Obesidade \\
Nefropatia de refluxo \\
\hline
\end{tabular}

*Anti-Inflamatórios Não Esteróides

Adaptada de: Glassrock RJ. Proteinuria. In: Glassrock RJ, Massry SJ, editors. Textbook of Nephrology. 3rd ed. Baltimore: Williams and Wilkins; 1995. p. 545-9.

teínas quando o doente está em ortostatismo e por uma excreção normal de proteínas quando o doente está em decúbito. ${ }^{3}$ A excreção diária de proteína nesta situação não ultrapassa, em regra, 1g/dia. É uma forma de proteinúria persistente, mas benigna, já que não é acompanhada de alterações da tensão arterial, da função renal, do sedimento urinário ou da imagiologia. ${ }^{15}$ Além disso, a histologia renal é muitas vezes normal ou com achados inespecíficos. A sua fisiopatologia não é conhecida, mas pensa-se estar relacionada com alterações da hemodinâmica glomerular e com activação neuro-humoral. Convém no entanto recordar que existe um componente ortostático em todas as formas de proteinúria. ${ }^{33}$

A proteinúria persistente, que se define como a que está presente em pelo menos duas avaliações, reflecte mais frequentemente doença renal estrutural ou doença sistémica (por exemplo, a insuficiência cardíaca pode estar associada a proteinúria ligeira a moderada, sendo mediada pelos niveis persistentemente elevados de angiotensina II e de noradrenalina que se observam nesta condição). Se for inferior a $3,5 \mathrm{~g} / \mathrm{dia}$ (não nefrótica), pode traduzir doença tubulo-intersticial ou a fase inicial de certas glomerulopatias; quando superior 3,5 g/dia (nefrótica) indica frequentemente doença glomerular (primária ou secundária) - Quadro II. ${ }^{25}$

\section{Algoritmo Diagnóstico de ProteinúrIA}

Quando se detecta proteinúria numa análise de rotina, há que excluir os falsos positivos (ver Tiras Teste/Sumária de Urina) e as situações clínicas que cursam com proteinúria transitória: febre, exercício físico, infecções urinárias... (Figura 2). Daí a necessidade de repetição da análise, pelo menos 2 a 3 vezes, antes de prosseguir com o estudo.

A realização de uma história clínica completa é fundamental, para 


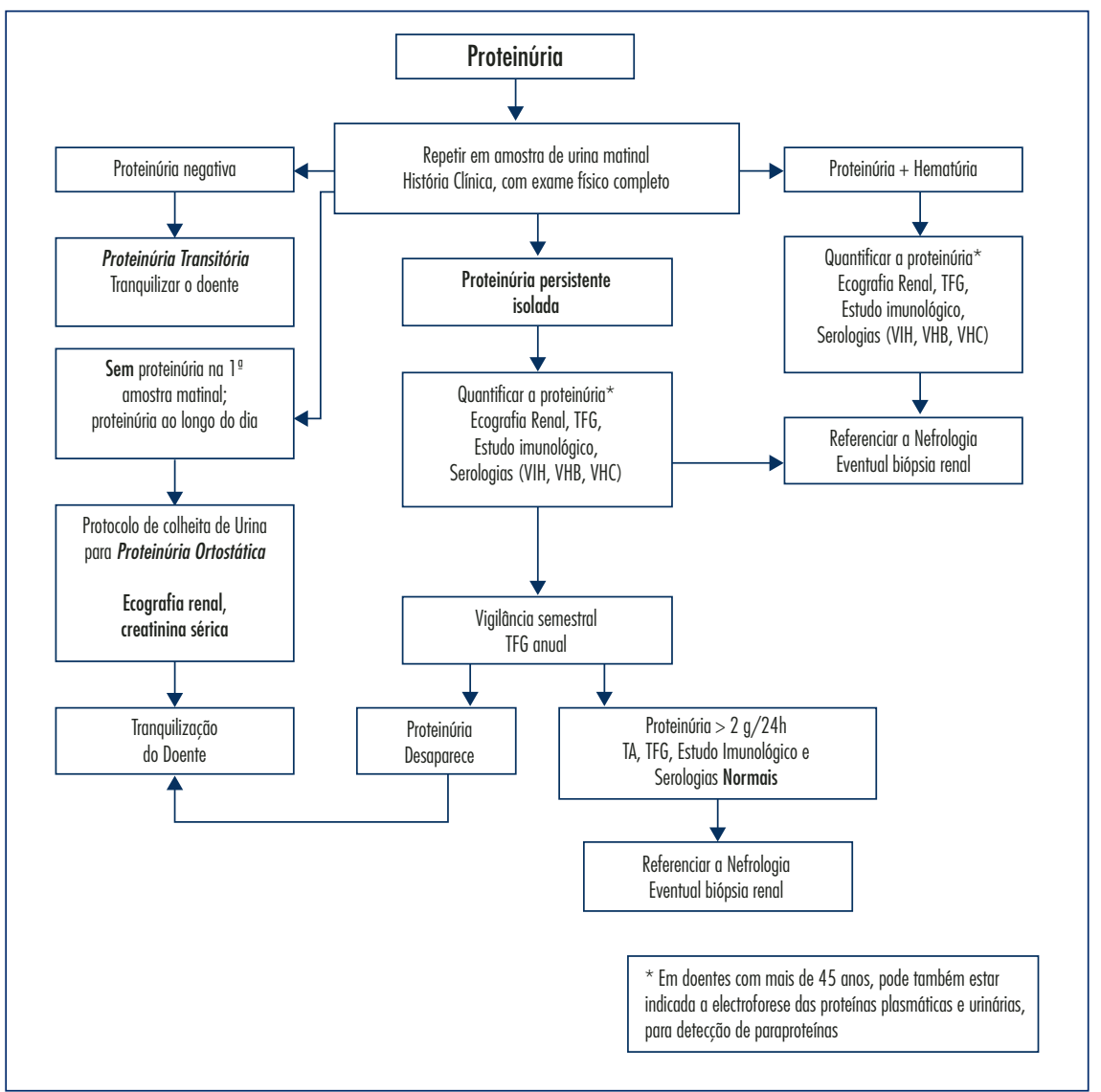

Figura 2. Abordagem ao doente com proteinúria

Adaptado de: Cameron JS. The Patient with proteinuria and/or haematuria. In: Davison A, Cameron S, Grunfeld JP, Ponticelli C, et al. editors. Oxford Textbook of Clinical Nephrology. 3rd ed. Oxford: Oxford University Press; 2005.

a identificação de doenças renais ou sistémicas como a diabetes mellitus, doenças cardiovasculares (insuficiência cardíaca, hipertensão...) ou mesmo doenças auto-imunes que possam justificar a proteinúria. Se a proteinúria se mantiver em análises repetidas (persistente) ou se for de 3 a 4+ logo no exame inicial de rotina, a investigação etiológica deve continuar com a quantificação da excreção diária de proteínas (em amostras de urina de 24 horas ou através da determinação da razão albumina/creatinina ou proteína total/creatinina em amostra de urina). Devido à influência do exercício na proteinúria deve-se aconselhar aos doentes actividade fisica moderada na véspera e no dia de colheita da amostra. ${ }^{15}$

Em presença de proteinúria persistente, em adolescentes ou adultos jovens, deve-se encarar a possibilidade de proteinúria ortostática (principalmente se associada a tensão arterial, função renal, sedimento urinário e ecografia normais). $\mathrm{O}$ seu diagnóstico assenta num protocolo próprio de colheita de urina durante 24 horas: $^{3}$

- a primeira urina da manhã deve ser desperdiçada;

- deve-se obter uma amostra de
$16 \mathrm{~h}$ de urina entre as 7 e as $23 \mathrm{~h}$, horas durante as quais o doente deve deambular; esta colheita deve ser terminada por uma micção às $23 \mathrm{~h}$;

- nas últimas $2 \mathrm{~h}$ da colheita diurna, o doente deve assumir uma posição de decúbito, para evitar a contaminação da amostra nocturna com urina formada em ortostatismo;

- a colheita nocturna deve decorrer entre as 23 e as $7 \mathrm{~h}$ do dia seguinte.

Para que se estabeleça este diagnóstico, é necessário que a excreção de proteínas seja normal quando o doente está na posição de decúbito (<50 mg em 8 h), não sendo suficiente observar-se apenas uma redução na excreção de proteínas. ${ }^{3}$

Como alternativa a este protocolo de colheita pode-se calcular a razão proteína/creatinina na primeira urina da manhã e em amostra colhida após período de deambulação. Em caso de proteinúria ortostática, a razão obtida na primeira urina da manhã é normal e a calculada na segunda amostra elevada. ${ }^{3}$

\section{Avaliação Laboratorial e Imagiológica}

Em todos os doentes com proteinúria persistente é necessário um estudo laboratorial para avaliar a gravidade da doença renal subjacente.

O sedimento urinário deve ser observado à microscopia óptica, em todos os doentes com proteinúria, de preferência em amostra de urina matinal. A associação entre proteinúria e hematúria microscópica deve alertar para a presença de lesão estrutural renal; o achado de cilindros eritrocitários e/ou de eritrócitos dismórficos (resultado de agressão celular osmótica no nefrónio), são muito sugestivos de doença glomerular (primária ou secundá- 
ria). Convém salientar que algumas doenças não-glomerulares se podem apresentar desta forma (necrose papilar, tuberculose renal, nefropatia de refluxo...). Em indivíduos idosos, a amiloidose e a diabetes são causas frequentes de hemato-proteinúria (em um terço dos doentes com nefropatia diabética pode surgir hematúria microscópica). ${ }^{21}$

Guando a análise do sedimento revelar doença renal, é necessário o envio a consulta de Nefrologia, para eventual biopsia renal e tratamento diferenciado. ${ }^{15}$

A análise laboratorial deve continuar com hemograma completo (com contagem diferencial), testes de função renal (creatinina e azoto ureico/ureia), doseamento das proteínas séricas (incluindo a albumina), doseamento dos electrólitos, cálculo do hiato aniónico, cálcio, fósforo, ácido úrico, bilirrubina, fosfatase alcalina, transaminases, ficha lípidica (colesterol total, LDL, HDL e triglicerídeos) e lactato-desidrogenase. O estudo laboratorial complementar tem sobretudo interesse na avaliação do grau de disfunção renal, podendo também sugerir a causa de proteinúria (diabetes, mieloma múltiplo... - nesta última situação pode ocorrer anemia, inversão da relação entre albumina/globulina, hipercalcemia ou mesmo redução do hiato aniónico).

Nas fases iniciais da DRC, as pequenas variações na Taxa de Filtração Glomerular (TFG) não se traduzem nos niveis séricos de creatinina. Assim pode ser necessário obter uma clearance da creatinina em urina de $24 \mathrm{~h}$ ou proceder ao seu cálculo (fórmulas de Cockcroft-Gault ou de MDRD - Quadro III - disponíveis gratuitamente em www.hdcn. com ou em www.spnefro.pt). Se a clearance da creatinina se apresentar reduzida (particularmente se

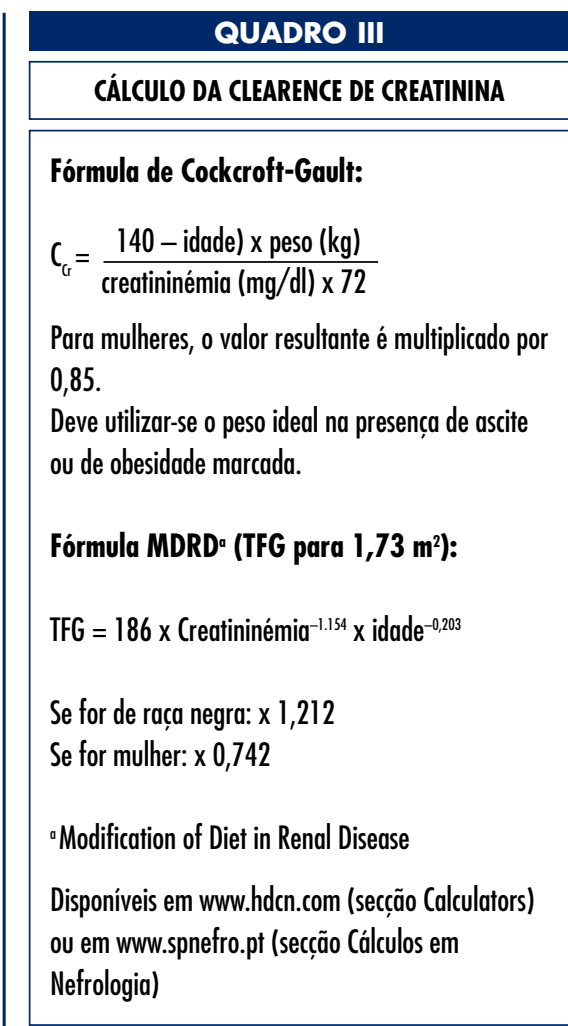

$<60 \mathrm{ml} / \mathrm{min})^{27}$ o doente deverá ser referenciado para consulta de $\mathrm{Ne}$ frologia.

Se após a investigação laboratorial inicial não se detectar uma causa óbvia para a proteinúria, deve-se proceder a um estudo imunológico com o doseamento dos anticorpos anti-nucleares (ANA), dos anticorpos anti-citoplasma de neutrófilo (ANCA), dos anticorpos anti-membrana basal glomerular (anti-MGB), dos níveis de complemento, das imunoglobulinas e da velocidade de sedimentação para avaliação de doenças auto-imunes ou linfoproliferativas. As correlações clínicas sumárias entre os perfis imunológicos e as doenças são apresentadas no Guadro IV.

Também o rastreio de certas doenças infecciosas causadoras de doença renal é importante na abor- dagem diagnóstica da proteinúria; destas salientam-se as infecções pelo Vírus da Imunodeficiência Humana (VIH), as infecções pelos Virus das hepatites B (VHB) ou C (VHC) e a sífilis.

Em doentes com idade superior a 45 anos, o estudo da proteinúria deve obrigatoriamente passar pela realização de electroforese das proteínas séricas e urinárias. A presença de proteinúria não detectável por tira teste e de insuficiência renal inexplicada, com anemia, hipercalcemia e dor óssea são sugestivos de discrasia plasmocitária. ${ }^{15}$

A ecografia renal e das vias urinárias é fundamental para excluir lesões estruturais do tracto urinário. Fornece informações acerca das dimensões dos rins, da existência ou não de cicatrizes pielonéfricas, de quistos renais ou de obstrução; além disso também ajuda na planificação da biopsia renal (a existência de rins bilateralmente pequenos, com múltiplas cicatrizes, contra-indica a sua realização).

\section{Biopsia renal}

Está indicada em todos os casos de proteinúria nefrótica, excepto naqueles em que, de acordo com a história e com o grau de envolvimento extra-renal, o diagnóstico possa ser evidente (amilóidose primária ou secundária, diabetes mellitus...). Nas situações de proteinúria ligeira/moderada (<0,5-1 g/dia), acompanhadas de tensão arterial, sedimento urinário e função renal normais, a biopsia renal não está indicada já que o prognóstico é favorável na maioria das vezes. No entanto, caso a proteinúria venha a agravar ou surjam alterações da função renal, do sedimento urinário ou hipertensão, a biopsia passa a estar indicada. ${ }^{34,35}$

A associação de hemato-protei- 
QUADRO IV

\begin{tabular}{|c|c|}
\hline \multicolumn{2}{|c|}{ CORRELAC̣ÃO ENTRE OS ACHADOS IMUNOLÓGICOS E AS PATOLOGIAS. } \\
\hline Imunologia & Correlação Clínica \\
\hline $\begin{array}{l}\text { C3 e CH50 diminuidos; C } 4 \text { normal, } \\
\text { TASO +, anti-DNAse +, Hipergamaglobulinémia }\end{array}$ & Glomerulonefrite pós-estreptocócica \\
\hline C3 diminuído, ANA +, ds-DNA + & Lúpus eritematoso sistémico \\
\hline $\begin{array}{l}\text { Depressão C3, C4, CH50, } \\
\text { Crioglobulinémia, serologias positivas } \\
\text { para HCV ou HBV }\end{array}$ & Crioglobulinémia \\
\hline Anti-corpos anti-membrana basal glomerular (MBG) & Doença anti-MBG / S. de Goodpasture \\
\hline c-ANCA & Granulomatose de Wegener \\
\hline c-ANCA/p-ANCA & Poliangeíte microscópica, Síndrome de Churg-Strauss \\
\hline p-ANCA & Glomerulonefrite crescêntica limitada ao rim \\
\hline ANCA negativo & Poliarterite nodosa clássica \\
\hline
\end{tabular}

Adaptada de: Brady HR, O'Meara Y, Brenner BM. Glomerular diseases. In: Kasper D, Braunwald E, Fauci A, Hauser S, Longo D, Jameson J, editors. Harrison's Principles of Internal Medicine. 16th ed. New York: McGraw Hill; 2004. p. 1674-94.

núria está muitas vezes associada a glomerulopatia primária ou secundária e pode justificar a realização de biopsia renal, principalmente quando associada a anomalias da função renal ou do estudo imunológico e na ausência de doença sistémica subjacente. $^{15}$

A decisão de realizar a biopsia não deve ser adiada, já que o prognóstico, em alguns casos, está dependente da histologia e da terapêutica precoce.

\section{Importância ClíNICA da Proteinúria}

Desde há cerca de um quarto de século que a proteinúria é vista como um marcador de doença glomerular, e que a sua magnitude reflecte directamente a extensão da lesão. ${ }^{15}$ Para além disso, a proteinúria também contribui directamente para a progressão da doença renal através de toxicidade tubular. As células tubulares epiteliais expostas às proteínas plasmáticas libertam uma variedade de citocinas pró-inflamatórias e de proteínas da matriz extrace- lular, que resultam em inflamação intersticial e fibrose. ${ }^{36}$ Desta forma se pode explicar o aparecimento e a importância de lesão tubulo-intersticial nas situações em que a agressão primária é dirigida ao glomérulo. ${ }^{37}$

A implicação da proteinúria na progressão da doença renal e como marcador na monitorização da terapêutica de reno-protecção é sugerida por uma variedade de estudos. Três estudos em doentes com DRC não-diabética (MDRD, ${ }^{38}$ Ramipril Efficacy in Nephropathy- REIN ${ }^{39} \mathrm{e}$ African-American Study of Kidney Disease and Hypertension - $\mathrm{AASK}^{40}$ ) demonstraram claramente que valores basais elevados de proteinúria se associavam a um mais rápido declínio da função renal. Do mesmo modo, estudos em doentes com nefropatia diabética defenderam que valores iniciais elevados da razão albumina/creatinina eram importantes predictores da progressão da doença renal (RENAAL, ${ }^{41}$ IDNT $^{42}$ ). Os mesmos estudos também provaram que nos doentes em que se conseguiu uma maior redução da proteinúria se observou um melhor prog- nóstico renal. ${ }^{38-42}$ Além disso, o grau de proteinúria residual que persiste após o tratamento com Inibidor da Enzima de Conversão da Angiotensina (IECA) ou com Antagonista do Receptor da Angiotensina II (ARA II) está também directamente relacionado com a evolução da função renal; ${ }^{43}$ uma meta-análise que englobou 1.860 doentes com DRC não-diabética mostrou que durante o tratamento anti-hipertensor, o nivel de proteinúria foi um importante factor na progressão da doença. ${ }^{44}$

A proteinúria é assim um marcador de risco renal na população geral e em doentes com DRC, antes e durante o tratamento. ${ }^{43}$ Por isso, as K/DOQI recomendam o tratamento de todos os doentes com proteinúria superior a $500-1.000 \mathrm{mg} /$ dia $(500-$ $-1.000 \mathrm{mg} / \mathrm{g}$ de creatinina), independentemente da co-existência de diabetes. ${ }^{45}$ Como a redução na excreção urinária de proteínas em curtos períodos de tempo se correlaciona com a preservação da função renal a longo prazo, a monitorização da proteinúria (cada 3 a 6 meses, após definição de um valor base) é fundamental na implementação das terapêuticas de reno-protecção. ${ }^{46}$

\section{Microalbuminúria e \\ Doença Cardiovascular}

De acordo com estudos recentes, para além da sua relação com a doença renal, a microalbuminúria é um importante factor de risco de doença e mortalidade cardiovascular, em doentes com ou sem diabetes e/ou hipertensão. O estudo HOPE (Heart Outcomes Prevention Evaluation), que envolveu mais de 9.000 doentes em risco de evento cardiovascular, demonstrou que a presença de microalbuminúria se associava a um aumento do risco de enfarte do miocárdio, de acidente vascular cerebral e de morte cardiovascular, 
em doentes com ou sem diabetes; para além disso também verificou que o aumento do risco era proporcional ao aumento absoluto da excreção urinária de albumina. ${ }^{47} \mathrm{Re}-$ sultados semelhantes foram obtidos no estudo LIFE, em doentes com hipertensão e evidência electrocardiográfica de hipertrofia do ventrículo esquerdo. ${ }^{48} \mathrm{O}$ estudo PREVEND, que, ao contrário dos anteriores, envolveu 40.548 indivíduos oriundos da população geral, também mostrou um aumento do risco relativo de mortalidade cardiovascular em 1,35 por cada duplicação do valor de excreção urinária de albumina. ${ }^{49}$

Embora apenas se considere microalbuminúria quando a excreção urinária diária de albumina ultrapassa os $30 \mathrm{mg}$ ( $30 \mathrm{mg} / \mathrm{g}$ de creatinina ou $20 \mu \mathrm{g} / \mathrm{min}$ ), alguns trabalhos publicados ao longo da última década (Third Copenhagen Heart Study, Framingham Heart Study) sugerem que niveis bem menores de albuminúria estão associados a um aumento do risco cardiovascular, aditivo aos factores de risco convencionais. ${ }^{50-52}$

Apesar destas evidências, a associação entre microalbuminúria e doença cardiovascular não está completamente esclarecida. A microalbuminúria em doentes sem diabetes parece ser a expressão renal de uma disfunção endotelial generalizada. De facto, nestes doentes, a vasodilatação em resposta a certos estímulos está comprometida. ${ }^{53}$ Niveis elevados de Factor de von Willebrand (FvW) foram encontrados em doentes com hipertensão e microalbuminúria, existindo uma correlação directa entre os níveis de FvW e a excreção urinária de albumina; como o FvW está associado a fenómenos trombóticos, o aumento dos seus niveis plasmáticos pode contribuir decisivamente para o au- mento do risco cardiovascular. ${ }^{54} \mathrm{Em}$ diabéticos também existe uma disfunção endotelial, que se agrava na presença de microalbuminúria. ${ }^{55} \mathrm{As}$ alterações induzidas na matriz extracelular pela hiperglicémia levam ao aumento da permeabilidade microvascular, que se traduzem a nível glomerular em microalbuminúria e a nivel vascular periférico na deposição aumentada de lipoproteínas. ${ }^{56}$

Atendendo ao aumento do risco cardiovascular na presença de microalbuminúria, as K/DOQI recomendam o seu rastreio não só em diabéticos, mas também na população não diabética em risco de DRC e de doença cardiovascular (hipertensão, sindrome metabólico). ${ }^{45} \mathrm{~A}$ existência de microalbuminúria permite a implementação / optimização de terapêuticas dirigidas à redução do risco cardiovascular e ao atraso na progressão da doença renal.

\section{TRATAMENTO}

As terapêuticas específicas das causas de proteinúria mencionadas saem fora do âmbito deste artigo. Aqui serão revistas as terapêuticas anti-proteinúricas com eficácia demonstrada no contexto da DRC.

O controlo da tensão arterial é fulcral na estratégia de redução da excreção urinária de proteínas, já que está provado que por si só tem efeitos anti-proteinúricos. As guidelines estabelecem o objectivo de 130/80 mmHg para os doentes renais crónicos, ${ }^{57}$ sendo no entanto desejáveis valores inferiores de tensão sistólica quando a proteinúria for superior a 0,5-1 g/dia ${ }^{40,44}$ (evitando no entanto valores de sistólica menores que 110 $\mathrm{mmHg}$, devido ao aumento do risco de progressão da doença renal). ${ }^{58}$

Nos doentes com proteinúria, o controlo da tensão arterial passa pela utilização de fármacos com actividade sobre o sistema renina-angiotensina-aldosterona (SRAA) IECA e ARA II. Estas duas classes atingem o efeito anti-proteinúrico através da redução da pressão intraglomerular, não existindo vantagem de uma relativamente à outra neste objectivo. É com base neste efeito que as K/DOQI recomendam a utilização de doses mais altas destes fármacos em doentes com DRC e proteinúria, uma vez que se potencia a renoprotecção, sem uma descida comparável dos níveis de tensão arterial. ${ }^{45}$ Seguindo esta linha de raciocínio, diversos estudos demonstraram que a associação IECA/ARA II potencia os efeitos anti-proteinúricos de cada uma destas classes de anti-hipertensores; ${ }^{59}$ esta é uma combinação a considerar sobretudo em doentes com controlo tensional precário. Deve haver no entanto alguma precaução no uso destas duas classes farmacológicas em doentes com DRC, pelos riscos acrescidos de hipercaliémia e de agravamento da retenção azotada.

Nestes doentes, sempre que a tensão arterial não se encontra dentro dos objectivos referidos (i.e. inferior a 130/80 mmHg) com a utilização de IECA e/ou ARA II, deve-se optar pela associação destes com um antagonista dos canais de cálcio não-dihidropiridínico (verapamil ou diltiazem), atendendo aos seus efeitos anti-proteinúricos intrínsecos. ${ }^{60}$

Componente essencial do tratamento não farmacológico da hipertensão, a restrição de sódio na dieta (para menos de 80-110 mmol/dia) tem igualmente efeito anti-proteinúrico, explicado não só pela descida da tensão arterial, mas também pelos efeitos benéficos na hemodinâmica glomerular ${ }^{61-63} \mathrm{Além}$ disso, a redução do aporte de sal aumenta a efi- 
cácia anti-proteinúrica dos IECA, ARA II e dos antagonistas dos canais de cálcio não-dihidropiridínicos. ${ }^{64}$ Do mesmo modo, a utilização de diuréticos (tiazídicos ou da ansa) também aumenta a renoprotecção proporcionada por estas classes farmacológicas, sobretudo quando são utilizadas em situações de elevada ingestão salina. ${ }^{65}$

Para além do seu conhecido efeito no atraso da progressão da doença renal diabética e não diabética, a restrição de proteínas na dieta (para um máximo de $0,8 \mathrm{~g} / \mathrm{kg}$ de peso/ /dia) também exerce uma acção anti-proteinúrica, aditiva à do bloqueio do SRAA. ${ }^{46,66}$

As estatinas também demonstraram efeito anti-proteinúrico; numa meta-análise de 15 estudos randomizados que envolveram 1.384 doentes, a utilização de estatinas associou-se a uma redução de 48 e $47 \%$ na albuminúria, naqueles com valores de base entre 30-299 e $>300 \mathrm{mg} /$ dia, respectivamente. ${ }^{67} \mathrm{O}$ seu efeito renoprotector é aditivo ao do bloqueio do SRAA; no entanto está ainda por definir a dose óptima para o efeito anti-proteinúrico e se existe ou não efeito de classe. ${ }^{46}$

Duas estratégias vantajosas na protecção cardiovascular e com eficácia anti-proteinúrica são a cessação tabágica e a perda de peso. Diversos estudos demonstraram a associação entre tabagismo e aumento da excreção urinária de proteínas, com a consequente aceleração da progressão da doença renal. ${ }^{68}$ Já a obesidade é um factor de risco independente para doença renal crónica; ${ }^{68,69}$ associa-se a um aumento na pressão intra-glomerular e assim à excreção aumentada de proteínas na urina. ${ }^{70}$

As terapêuticas apresentadas permitirão ao clínico a redução da proteinúria, de modo a atingir niveis inferiores a $500 \mathrm{mg} /$ dia (ou $500 \mathrm{mg}$ / /g de creatinina). De todas elas, a utilização de IECA e/ou ARA II foi aquela que melhores resultados apresentou, devido ao controlo da tensão arterial e à acção anti-proteinúrica intrínseca. As modificações no estilo de vida acima referidas e a utilização de estatinas devem também ser consideradas, já que potenciam as acções na proteinúria das duas classes farmacológicas mencionadas e contribuem decisivamente para a redução do risco cardiovascular global.

\section{CONCLUSÃo}

O significado clínico da proteinúria é muito variável. A utilização de um algoritmo diagnóstico como o proposto ajudará o clínico a distinguir as causas mais frequentes e benignas, das causas mais raras e patológicas. Os doentes em que a causa de proteinúria permanece desconhecida após avaliação sistemática, deverão ser referenciados à consulta de Nefrologia. Isto é sobretudo válido para os doentes com proteinúria persistente, na faixa nefrótica, sem causa sistémica identificável e que muito provavelmente têm uma disfunção glomerular.

A relativa facilidade com que a proteinúria pode ser detectada e monitorizada permite ao médico identificar indivíduos em estádios precoces de DRC. Para além da sua importância prognóstica, a detecção de proteinúria permite a utilização de terapêuticas renoprotectoras (anti-proteinúricas), com benefício comprovado a longo prazo em doentes renais crónicos. Considerando o aumento da prevalência da DRC na população geral, o Médico Especialista em Medicina Geral e Familiar tem um papel preponderante na identi- ficação dos doentes em risco de doença renal, bem como na monitorização dos factores de risco a ela associados (nomeadamente da proteinúria).

\section{REFERÊNCIAS BIBLIOGRÁFICAS}

1. Wagner DK, Harris T, Madans JH. Proteinuria as a biomarker: risk of subsequent morbidity and mortality. Environ Res 1994 Aug; 66 (2): 160-72.

2. Boulware LE, Jaar BG, Tarver-Carr ME, Brancati FL, Powe NR. Screening for proteinuria in US adults: a cost-effectiveness analysis. JAMA 2003 Dec 17; 290 (23): 3101-14.

3. Rose BD, Post TW. Proteinuria: the primary care approach. Disponivel em: URL. http://www.uptodate.com [acedido em 21/04/2008].

4. Rose BD, Post TW, Measurement of urinary protein excretion. Disponivel em: URL. http://www.uptodate.com [acedido em 21/04/2008].

5. Krimholtz M, Smith A, Viberti G. Accurate measurement of albuminuria at reduced cost. Nephrol Dial Transplant 2004 Jul; 19 (7): 1934-5.

6. Floege J, Feehally J. Introduction to glomerular disease: clinical presentations. In: Feehally J, Floege J, Johnson R, editors. Comprehensive Clinical Nephrology. 3rd ed. Philadelphia: Mosby; 2007. p. 193-207.

7. Rose BD. Examination of the Urine. In: Rose BD, editor. Pathophysiology of renal disease. 2nd ed. New York: McGrawHill; 1987. p. 11-6.

8. Rose BD, Evaluation of isolated proteinuria in adults. Disponivel em: URL. http://www.uptodate.com [acedido em 21/04/2008].

9. Raats CJ, van den Borne J, Berden JHM. Glomerular heparan sulfate alterations: mechanisms and relevance for proteinuria. Kidney Int 2000 Feb; 57 (2): 385400.

10. Kanwar YS, Liu ZZ, Kashihara N, Wallner EI. Current status of structural and functional basis of glomeRular filtration and proteinuria. Semin Nephrol 1991 Jul; 11 (4): 390-413.

11. Brady HR, O'Meara Y, Brenner BM. Glomerular diseases. In: Kasper D, Braunwald E, Fauci A, Hauser S, Longo D, Ja- 
meson J, editors. Harrison's Principles of Internal Medicine. 16th ed. New York: McGraw Hill; 2004. p.1674-94.

12. Lahdenkari AT, Lounatmaa K, Patrakka J, Holmberg C, Wartiovaara J, Kestilä M, et al. Podocytes are firmly attached to glomerular basement membrane in kidneys with heavy proteinuria. J Am Soc Nephrol 2004 Oct; 15 (10): 2611-8.

13. Myers BD, Nelson RG, Tan M, Beck GJ, Bennett PH, Knowler WC, et al. Progression of overt nephropathy in non-insulin dependent diabetes. Kidney Int 1995 Jun; 47 (6) : 1781-8.

14. Ota Z, Shikata K, Ota K. Nephrotic tunnels in glomerular basement membrane as revealed by new electron microscopic method. J Am Soc Nephrol 1994 Jun; 4 (12): 1965-73.

15. Cameron JS. The patient with proteinúria and/or haematuria. In: Davison A, Cameron S, Grunfeld JP, Ponticelli C, editors. Oxford Textbook of Clinical Nephrology. 3rd ed. Oxford: Oxford University Press; 2005. p. 389-414.

16. Norden AG, Lapsley M, Lee PJ, Pusey CD, Scheinman SJ, Tam FW, et al. Glomerular protein sieving and implications for renal failure in Fanconi syndrome. Kidney Int 2001 Nov; 60 (5): 1885-92.

17. Glassrock RJ. Proteinuria. In: Glassrock RJ, Massry SJ, editors. Textbook of Nephrology. 3rd ed. Baltimore: Williams and Wilkins; 1995. p. 545-9.

18. Fogazzi GB, Pirovano B. Urinalysis. In: Comprehensive Clinical Nephrology. 3rd ed. new York:Mosby; 2007. p. 35-50.

19. Morcos SK, el-Nahas AM, Brown P, Haylor J. Effect of iodinated water soluble contrast media on urinary protein assays. BMJ 1992 Jul 4; 305 (6844): 29-40.

20. Constantiner M, Sehgal AR, Humbert L, Constantiner D, Arce L, Sedor JR, et al. A dipstick protein and specific gravity algorithm accurately predicts pathological proteinuria. Am J Kidney Dis 2005 May; 45 (5): 833-41.

21. Fogazzi GB. Urinalisys and microscopy. In: Davison A, Cameron S, Grunfeld JP, Ponticelli C, editors. Oxford Textbook of Clinical Nephrology. 3rd ed. Oxford: Oxford University Press. 2005. p. 23-45.

22. Comper WD, Osicka TM. Detection of urinary albumin. Adv Chronic Kidney Disease 2005 Apr: 12 (2): 170-6.

23. Gross JL, Azevedo MJ, Silveiro SP, Canani LH, Caramori ML, Zelmanovitz T.
Diabetic nephropathy: diagnosis, prevention and treatment. Diabetes Care 2005 Jan; 28 (1): 164-76.

24. American Diabetes Association. Nephopathy in diabetes (position statement). Diabetes Care 2004 Jan; 27 Suppl 1: S79-S83.

25. Carroll MF, Temte JL. Proteinuria in adults: a diagnostic approach. Am Fam Physician 2000 Sep 15; 62 (6): 1333-40.

26. Eknoyan G, Hostetter T, Bakris GL, Hebert L, Levey AS, Parving HH, et al. Proteinuria and other markers of chronic kidney diseae: a position statement of the $\mathrm{Na}$ tional Kidney Foundation (NKF) and the National Institute of Diabetes and Digestive and Kidney Diseases (NIDDK). Am J Kidney Dis 2003 Oct; 42 (4): 617-22.

27. National Kidney Foundation. K/ /DOQI clinical practice guidelines for chronic kidney disease: evaluation, classification and stratification. Am J Kidney Dis 2002 Feb; 39 (2 Suppl 1): S1-S245.

28. Chitalia VC, Kothari J, Wells EJ, Livesey JH, Robson RA, Searle M, et al. Costbenefit analysis and prediction of 24-hour proteinuria from the spot urine proteincreatinine ratio. Clin Nephrol 2001 Jun; 55 (6): 436-47.

29. Mattix HJ, Hsu CY, Shaykevich S, Curhan G. Use of the albumin/creatinine ratio to detect microalbuminuria: implications of sex and race. J Am Soc Nephrol 2002 Apr; 13 (4): 1034-9.

30. Robinson RR. Isolated proteinuria in asymptomatic patients. Kidney Int 1980 Sep; 18 (3): 395-406.

31. Carter JL, Tomson CR, Stevens PE, Lamb EJ. Does urinary tract infection cause proteinuria or microalbuminuria? A systematic review. Nephrol Dial Transplant 2006 Nov; 21 (11): 3031-7.

32. Redon J. Measurement of microalbuminuria: what the nephrologist should know. Nephrol Dial Transplant 2006 Mar; 21 (3): 573-6.

33. Wan LL, Yano S, Hiromura K, Tsukada Y, Tomono S, Kawazu S. Effects of posture on creatinine clearance and protein excretion in patients with various renal diseases. Clin Nephrol 1995 May; 43 (5): 312-7.

34. Hall CL, Bradley R, Kerr A, Attoti R, Peat $D$. Clinical value of renal biopsy in patients with asymptomatic microscopic hematuria with and without low-grade proteinuria. Clin Nephrol 2004 Oct; 62 (4):
267-72.

35. Fuiano G, Mazza G, Comi N, Caglioti A, De Nicola L, Iodice C, et al. Current indications for renal biopsy: a questionnaire-based survey. Am J Kidney Dis 2000 Mar; 35 (3): 448-57.

36. Kairaitis LK, Harris DC. Tubular interstitial interactions in proteinuric renal diseases. Nephrology 2001 Oct; 6 (5): 198207.

37. Abbate M, Zoja C, Remuzzi G. How does proteinuria cause progressive renal damage? J Am Soc Nephrol 2006 Nov; 17 (11): 2974-84.

38. Peterson JC, Adler S, Burkart JM, Greene T, Hebert LA, Hensicker LG, et al. Blood pressure control, proteinuria, and the progression of renal disease. The Modification of Diet in Renal Disease Study. Ann Intern Med 1995 Nov 15; 123 (10): 754-62.

39. Gruppo Italiano di Studi Epidemiologici in Nefrologia. Randomised placebocontrolled trial of effect of ramipril on decline in glomerular filtration rate and risk of terminal renal failure in proteinuric, nondiabetic nephropathy. Lancet 1997 Jun 28; 349 (9069): 1857-63.

40. Lea J, Greene T, Hebert L, Lipkowitz M, Massry S, Middleton J, et al. The relationship between magnitude of proteinuria reduction and risk of end-stage renal disease: results of the African American Study of Kidney Disease and Hypertension. Arch Intern Med2005 Apr 25; 165 (8): 947-53.

41. de Zeeuw D, Remuzzi G, Parving $\mathrm{HH}$, Keane WF, Zhang Z, Shahinfar S, et al. Proteinuria, a target for renoprotection in patients with type 2 diabetic nephropathy: lessons from RENAAL. Kidney Int 2004 Jun; 65 (6): 2309-20.

42. Atkins RC, Briganti EM, Lewis JB, Hunsicker LG, Braden G, Champion de Crespigny, et al. Proteinuria reduction and progression to renal failure in patients with type 2 diabetes mellitus and overt nephropathy. Am J Kidney Dis 2005 Feb; 45 (2): 281-7.

43. Taal MW, Brenner BM. Predicting initiation and progression of chronic kidney disease: developing renal risk scores in CKD. Kidney Int 2006 Nov; 70 (10): 1694705.

44. Jafar TH, Stark PC, Schmid CH, Landa M, Maschio G, Marcantoni C, et al. Proteinuria as a modifiable risk factor for the progression of non-diabetic kidney dise- 
ase. Kidney Int 2001 Sep; 60 (3): 1131-40. 45. National Kidney Foundation. K/ /DOQI clinical practice guidelines on hypertension and antihypertensive agents on chronic kidney disease. Am J Kidney Dis 2004 May; 43 (5 Suppl 19: S1-290.

46. Palmer BF. Proteinuria as therapeutic target in patients with chronic kidney disease. Am J Nephrol 2007 May; 27 (3): 287 $-93$.

47. McQueen MJ, Gerstein HC, Pogue J, Mann JF, YusufS. Reevaluation by highperformance liquid chromatography: clinical significance of microalbuminuria in individuals at high risk of cardiovascular disease in the Heart Outcomes Prevention Evaluation (HOPE) Study. Am J Kidney Dis 2006 Dec; 48 (6): 889-96.

48. Wachtell K, Ibsen H, Olsen MH, Borch-Johnsen K, Lindholm LH, Mogensen $\mathrm{CE}$, et al. Albuminuria and cardiovascular risk in hypertensive patients with left ventricular hypertrophy: the LIFE study. Ann Intern Med 2003 Dec 2; 139 (11): 901-6.

49. Hillege HL, Fidler V, Diercks GF, van Gilst WH, de Zeeuw D, van Veldhuisen DJ, et al. Urinary albumin excretion predicts cardiovascular and noncardiovascular mortality in general population. Circulation 2002 Oct 1; 106 (14): 1777-82.

50. Klausen K, Borch-Johnsen K, FeldtRasmussen B, Jensen G, Clausen P, Scharling $\mathrm{H}$, et al. Very low levels of microalbuminuria are associated with increased risk of coronary heart disease and death independently of renal function, hypertension, and diabetes. Circulation 2004 Jul 6; 110 (1): $32-5$.

51. Wang TJ, Evans JC, Meigs JB, Rifai $\mathrm{N}$, Fox CS, D’Agostino RB, et al. Low-grade albuminuria and the risks of hypertension and blood pressure progression. Circulation 2005 Mar 22; 111 (11): 1370-6.

52. Arnlöv J, Evans JC, Meigs JB, Wang TJ, Fox CS, Levy D, et al. Low-grade albuminuria and incidence of cardiovascular disease events in nonhypertensive and nondiabetic individuals: the Framingham Heart Study. Circulation 2005 Aug 16; 112 (7): 969-75.

53. Clausen P, Jensen JS, Jensen G, Borch-johnsen K, Feldt-Rasmussen B. Elevated urinary albumin excretion is associated with impaired arterial dilatory capacity in clinically healthy subjects. Circulation 2001 Apr 10; 103 (14): 1869-74.

54. Pedrinelli R, Giampietro O, Carmas- si F, Melillo E, Dell'Omo G, Catapano G, et al. Microalbuminuria and endothelial dysfunction in essential hypertension. Lancet 1994 Jul 2; 344 (8914):14-8.

55. Cosson E, Pham I, Valensi P, Pariès J, Attali JR, Nitenberg A. Impaired coronary endothelium-dependent vasodilation is associated with microalbuminuria in patients with type 2 diabetes and angiographically normal coronary arteries. Diabetes Care 2006 Jan; 29 (1): 107-12.

56. Rose BD, Bakris GL. Microalbuminuria and cardiovascular disease. Disponivel em: URL. http://www.uptodate.com [acedido em 21/04/2008].

57. Chobanian AV, Bakris GL, Black HR, Cushman WC, Green LA, Izzo JL Jr, et al. The Seventh Report of the Joint National Committee on Prevention, Detection, Evaluation and Treatment of High Blood Pressure: The JNC VII Report. JAMA 2003 May 21; 289 (19): 2560-72.

58. Palmer BF. Renal dysfunction complicating the treatment of hypertension. N Engl J Med 2002 Oct 17; 347 (16): 1256$-61$.

59. Wolf G, Ritz E. Combination therapy with ACE inhibitors and angiontensin II receptor blockers to halt the progression of chronic renal disease: pathophysiology and indications. Kidney Int 2005 Mar; 67 (3): 799-812.

60. Bakris GL, Weir MR, Secic M, Campbell B, Weis-McNulty A. Differential effects of calcium antagonist subclasses on markers of nephropathy progression. Kidney Int 2004 Jun; 65 (6):1991-2002.

61. Swift PA, Markandu ND, Sagnella GA, He FJ, MacGregor GA. Modest salt reduction reduces blood pressure and urine protein excretion in black hypertensives: a randomized control trial. Hypertension 2005 Aug; 46 (2): 308-12.

62. Jones-Burton C, Mishra SI, Fink JC, Brown J, Gossa W, Bakris GL, et al. An in-depth review of the evidence linking dietary salt intake and progression of chronic kidney disease. Am J Nephrol 2006 Jul; 26 (3): 268-75.

63. Mishra SI, Jones-Burton C, Fink JC, Brown J, Bakris GL, Weir MR. Does dietary salt increase the risk for progression of kidney disease? Curr Hypertens Rep 2005 Oct; 7 (5): 385-91.

64. Weir MR. Is the low protein diet or simply the salt restriction? Kidney Int 2007 Feb; 71 (3): 188-90.
65. Esnault VL, Ekhlas A, Delcroix C, Moutel MG, Nguyen JM. Diuretic and enhaced sodium restriction results in improved anti-proteinuric response to RAS blocking agents. J Am Soc Nephrol 2005 Feb; 16 (2): 474-81.

66. Gansevoort RT, de Zeeuw D, de Jong PE. Additive anti-proteinuric effect of ACE inhibition and a low-protein diet in human renal disease. Nephrol Dial Transplant 1995 Apr; 10 (4): 497-504.

67. Douglas K, O'Malley PG, Jackson JL. Meta-analysis: the effect of statins on albuminuria. Ann Intern Med 2006 Jul 18; 145 (2):117-24.

68. Halimi JM, Giraudeau B, Vol S, Cacès $\mathrm{E}$, Nivet $\mathrm{H}$, Lebranchu $\mathrm{Y}$, et al. Effects of current smoking and smoking discontinuation on renal function and proteinuria in the general population. Kidney Int 2000 Sep; 58 (3): 1285-92.

69. Navarro-Díaz M, Serra A, Romero R, Bonet J, Bayés B, Homs M, et al. Effect of drastic weight loss after bariatric surgery on renal parameters in extremely obese patients: long-term follow-up. J Am Soc Nephrol 2006 Dec; 17 (12 Suppl 3): S213-7.

70. Hsu CY, McCulloch CE, Iribarren C, Darbinian J, Go AS. Body mass index and risk for end-stage renal disease. Ann Intern Med 2006 Jan 3; 144 (1): 21-8.

\section{Endereço para correspondência} Francisco Ferrer Rua Flávio Rodrigues, $n^{\circ} 53,1^{\circ}$ esquerdo 3000-550 Coimbra

E-mail: franciscodina@gmail.com 


\section{ABSTRACT}

Introduction: Proteinuria is a common laboratorial finding in asymptomatic adults, which cannot be discounted in any circumstance. Dipstick urinalysis is by far the most used method for the detection of proteinuria, but because it has a high degree of false positive results, one should use other methods in its confirmation/follow up.

Objectives: To perform a revision of the physiopathologic basis of proteinuria and of the methods currently used in its detection and quantification. To discuss its clinical importance and to present a possible diagnostic algorithm. To review the specific therapies, mainly in the context of Chronic Kidney Disease (CKD).

Methods: We searched Pubmed for original articles, reviews and meta-analysis until April 2007. We also considered reference textbooks in Nephrology and Internal Medicine. Overall 63 articles were included.

Conclusions: An algorithmic approach helps in distinguishing between benign causes (febrile disease, physical exercise, dehydration. .. from other rarer, but more serious ones (glomerulopathies, monoclonal gammopathies). The detection of proteinuria in routine examinations must be confirmed, and in case of persistence, must be followed by a quantitative measurement (24-hour urine specimen or protein-to-creatinine ratio on a random urine specimen). Patients with persistent proteinuria, in whom the underlying etiology remains unclear after a thorough medical investigation, should be referred to a Nephrology consultation. In patients with CKD, early detection and treatment of asymptomatic proteinuria improves short and long-term prognosis. Considering the increasing prevalence of CKD in the general population, the General Practitioner plays an important role in identification of individuals at risk and in monitoring the associated risk factors, namely proteinuria.

Keywords: Proteinuria; Microalbuminuria; Chronic Kidney Disease. 